\title{
Meyerson Phenomenon Over Nuchal Nevus Simplex
}

\author{
Ada Claret-de Castro ${ }^{1}$, Marc Mir-Bonafé2, José María Mir-Bonafé3, Juan Francisco Mir-Bonafét
}

1 Department of Pediatrics, Hospital General de Granollers, Barcelona, Spain

2 Department of Dermatology, Hospital Universitario Central de Asturias, Oviedo, Spain

3 Department of Dermatology, Clínica Juaneda, Palma de Mallorca, Spain

4 Department of Dermatology, Hospital Son Llàtzer, Palma de Mallorca, Spain

Key words: Meyerson phenomenon, nevus simplex, salmon patch, capillary malformation, eczematous changes

Citation: Claret-de Castro A, Mir-Bonafé M, Mir-Bonafé JM, Mir-Bonafé JF. Meyerson phenomenon over nuchal nevus simplex. Dermatol Pract Concept. 2021;11(1):e2020098. DOI: https://doi.org/10.5826/dpc.1101a98

Accepted: June 16, 2020; Published: December 7, 2020

Copyright: (02020 Claret-de Castro et al. This is an open-access article distributed under the terms of the Creative Commons Attribution License BY-NC-4.0, which permits unrestricted noncommercial use, distribution, and reproduction in any medium, provided the original author and source are credited.

Funding: None.

Competing interests: The authors have no conflicts of interest to disclose.

Authorship: All authors had full access to all of the data in the study and take responsibility for the integrity of the data and the accuracy of the data analysis.

Corresponding author: Juan Francisco Mir-Bonafé, MD, Department of Dermatology, Hospital Son Llàtzer, Carretera Manacor, PK4, Palma de Mallorca, Spain. Email: joanmirbonafe@gmail.com

\section{Case Presentation}

Two infants aged 11 and 5 months consulted for eczematous plaques on the nape. Their parents reported that the lesions had developed over previous erythematous stains. Both cases corresponded to eczematous changes over nevus simplex, known as Meyerson phenomenon (Figure 1).
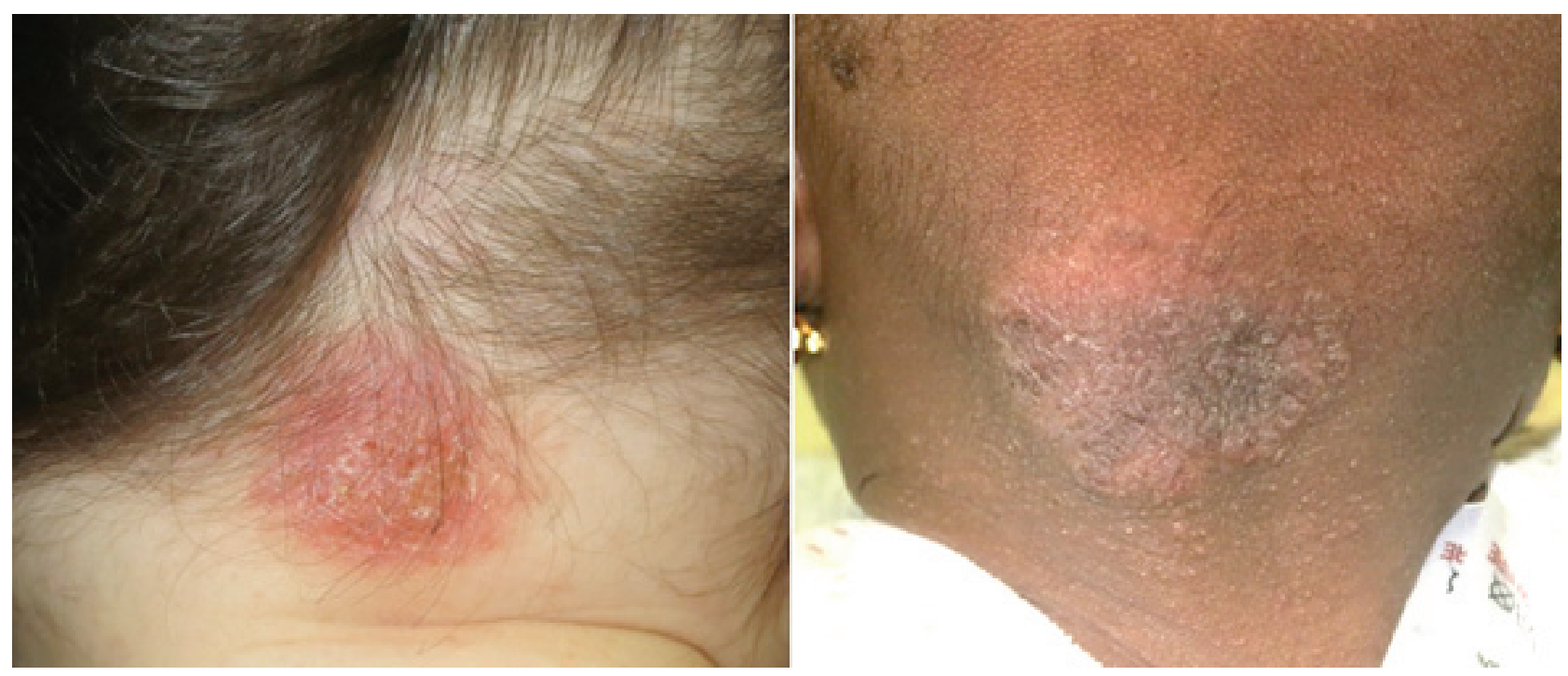

Figure 1. Two cases of Meyerson phenomenon over nuchal nevus simplex. 


\section{Teaching Point}

Meyerson phenomenon is defined as a spontaneous eczematous reaction within an overlying skin lesion. This phenomenon was first reported in melanocytic lesions [1]; however, it has also been related to seborrheic keratosis, dermatofibroma, molluscum contagiosum, and many other lesions. Although many hypotheses have been proposed, its origin is still unknown, and its relationship with atopic dermatitis remains controversial. Even though Meyerson phenomenon over capillary malformations is not frequent, it has been associated with nevus simplex [2,3], port-wine stains [4], and trunk and limb capillary malformations [5]. Exceptionally, it has been reported after laser treatment [4]. Although its diagnosis is clinical, in doubtful cases we may perform histopathological study. Histopathological findings include characteristic features of eczema such as spongiosis, acanthosis, parakeratosis, and superficial dermal lymphocytic infiltrate overlying capillary ectasias [1,5]. Prognosis is good, and topical corticosteroids are usually successfully used to treat the eczema. Nevertheless, some lesions may recur after treatment discontinuation, and pulsed dye laser therapy sometimes may be needed $[2,5]$.

\section{References}

1. Loh J, Kenny P. Meyerson phenomenon. J Cutan Med Surg. 2010;14(1):30-32. DOI: 10.2310/7750.2009.08065. PMID: 20128988.

2. Tay YK, Morelli J, Weston WL. Inflammatory nuchal-occipital port-wine stains. J Am Acad Dermatol. 1996;35(5 Pt 2):811-813. DOI: 10.1016/s0190-9622(96)90090-0. PMID: 8912592.

3. Rozas-Muñoz E, Frieden IJ, Roé E, Puig L, Baselga E. Vascular stains: proposal for a clinical classification to improve diagnosis and management. Pediatr Dermatol. 2016;33(6):570-584. DOI: 10.1111/pde.12939. PMID: 27456075.

4. Pavlovic MD, Adamic M. Eczema within port wine stain: spontaneous and laser-induced Meyerson phenomenon. Acta Dermatovenerol Alp Pannonica Adriat. 2014;23(4):81-83. DOI: 10.15570/actaapa.2014.20. PMID: 25527042.

5. Kim SJ, Kim YC. Eczema within a capillary malformation: a case of Meyerson phenomenon. Ann Dermatol. 2016:28(6):781-782. DOI: 10.5021/ad.2016.28.6.781. PMID: 27904286. 